\title{
Flores Escalante, Justo Miguel, Soberanía y excepcionalidad, la integración de Yucatán al estado mexicano, 1821-1848, México, El Colegio de México, Centro de Estudios Históricos, 2017, 312 pp., ISBN: 978-607-628-227-4.
}

\section{Maria Cecilia Zuleta*}

En el Golfo de México hacia el sureste, pero apuntando hacia el norte - hacia Luisiana y Nueva Orleans - se ubica la península de Yucatán, corazón del área maya, incomunicada por tierra con el macizo central mexicano hasta entrado el siglo xx, y frontera abierta hacia el gran Caribe británico, español y francés: Florida, Cuba, Puerto Rico, Belice y las Antillas. Esta aparente "periferia" de la península yucateca en relación con la zona central de México contrasta con los datos de su dinámica articulación al eje geo-económico Golfo-Caribe desde el siglo XVI, por un lado, y con el notable interés que ha despertado su pasado etnohistórico, social y agrario de los tiempos prehispánicos al arranque de su auge como polo turístico internacional en la actualidad. ${ }^{1}$

La singularidad histórica de la península yucateca es perceptible desde la época de auge de la civilización maya, y ha atraído a propios y extraños, yucatecos, mexicanos y extranjeros, como evidencian los escritos de los cronistas de indias ${ }^{2}$ y los numerosos estudios sobre su historia del siglo XIX (de Justo Sierra O’Reilly, de Eligio Ancona, el presbítero Crescencio Carrillo y Ancona, Albino Acereto y Joaquín Baranda, entre otros). A ellos debe sumarse el flujo continuo de viajeros, periodistas y científicos europeos y americanos desde mediados del siglo XIX, ${ }^{3}$ y después — desde fines de la primera guerra

* Centro de Estudios Históricos, El Colegio de México, correo electrónico: mczuleta@colmex.mx

1 Joseph, Rediscovering the Past at Mexico's Periphery, discute a profundidad estas contradicciones.

2 Dos ejemplos: Diego de Landa, Relación de las cosas de Yucatán, de mediados del siglo XVI, y Diego López de Cogolludo, Historia de Yucatán, de 1688.

3 Uno de los más conocidos: Stephens, Viaje a Yucatán, 1841-1842. Son numerosos los relatos de viajeros por la península durante la segunda mitad del siglo XIX. Para comienzos 
mundial - el desarrollo de proyectos de internacionales multidisciplinarios de investigación, financiados por universidades y fundaciones filantrópicas y culturales estadounidenses y europeas. Al lado de la monumental publicación de la Enciclopedia Yucatanense para conmemorar los cuatro siglos de la fundación de las ciudades de Mérida y Campeche entre 1944 y 1947, ${ }^{4}$ y de la riqueza documental de los estudios precursores de Ignacio Rubio Mañé y Silvio Zavala sobre la historia social y política de la península y sus dos ciudades principales, Campeche y Yucatán, se suma un vasto y diverso corpus de literatura histórica y socio-antropológica sobre su sociedad indígena y mestiza, ${ }^{5}$ y sobre el episodio de coincidencia entre la revolución agrarista y el auge exportador del henequén, indiscutible primera exportación agrícola del país entre 1880 y $1918 .{ }^{6}$

Después de estudios pioneros en la segunda posguerra y hasta los años sesenta, las décadas de los setenta y ochenta vieron un verdadero boom de estudios yucatecos y del área maya en la academia estadounidense, agregando ello otro elemento distintivo: un pronunciado interés historiográfico en el devenir yucateco, que contrasta con la atención más dispersa que han recibido otras zonas y estados del país (el noreste, el noroccidente y la costa pacífica sur, por ejemplo). Por eso, hace casi medio siglo, un reconocido y prolífico historiador se preguntaba si no era ocioso "siendo la historia yucateca una de las más estudiadas" sumar un nuevo estudio del siglo xIX en el cual confluyeran, en un amplio marco, la historia política, la económica y la diplomática, con España, Estados Unidos, Cuba y Gran Bretaña. ${ }^{7}$ La misma pregunta podríamos plantearnos hoy frente al recién publicado Soberanía y excepcionalidad, la integración de Yucatán al Estado Mexicano, 1821-1848, de Justo Flores Escalante. La respuesta es otra: antes que ocioso, Soberanía $y$ excepcionalidad... es un estudio que presenta un invaluable soporte documental original, expone una clara argumentación y un análisis inteligente que consigue destacar perfilándose como una obra de impacto historiográfico.

En primer lugar, destaca la pertinencia de las preguntas de Soberanía y excepcionalidad ..., originales y bien planteadas. Es conocido que desde la caída

del siglo xx y las campañas científicas estadounidenses, véase Palacios, "Los bostonians, Yucatán y los primeros rumbos de la arqueología americanista estadounidense, 1875-1894", pp. 105-193.

$4 \quad$ Yucatán ha sido uno de los pocos estados de México (también Chiapas, en 1940) que publicó una obra enciclopédica de su propia geografía, cultura e historia, la Enciclopedia Yucatanense, de ocho volúmenes y cerca de 50 autores, coordinada por Carlos Echánove Trujillo, bajo el auspicio del gobierno estatal, entre los años 1944 y 1947. Véase: "Yucatán en el tiempo", <https://es.wikipedia.org/wiki/Yucat\%C3\%A1n_en_el_tiempo>, [consultado el 2 de julio de 2018].

5 Sólo por mencionar algunos de los autores que han iluminado la etnohistoria peninsular: Sergio Quezada, Nancy Farris, Dorothy Tanck de Estrada, Robert Patch, Terry Rugeley.

El rico y diverso corpus es amplísimo, imposible de referir aquí.

González Navarro, en el prólogo de Raza y Tierra. La guerra de castas y el henequén, p. 3. 
de la metrópoli española la península de Yucatán mantuvo una complicada relación con el resto de lo que había sido el territorio de la Nueva España, aunque esta dinámica se remontaba a la suspensión del situado que apoyó a la Capitanía General de Yucatán desde Cuba entre 1793 y 1808, y a las tensiones territoriales, mercantiles y militares que impulsó la creación de la Intendencia de Mérida de Yucatán (con sus tres provincias, Campeche, Mérida y Tabasco).

Las discordias y desencuentros de las elites de Yucatán se plasmaron en conflictos y varias rupturas con las autoridades y gobiernos en México, centralistas y federalistas, a las que siguieron sucesivas reincorporaciones, unas menos espinosas y dramáticas que otras, desde la vigencia de la Constitución de Cádiz hasta la guerra con Estados Unidos y el estallido de una guerra de castas en 1847. Numerosos estudios vincularon estos conflictos, en principio, a las tensiones étnicas y transformaciones productivas y los circuitos mercantiles de la península y la región Circuncaribe en el período, y con la presencia del comercio español en Cuba, al lado de la expansión del comercio británico entre Belice y las Antillas, el crecimiento del comercio francés y ascenso del tráfico marítimo estadounidense. ${ }^{8}$ Una supuesta condición de excepcionalidad de la península de Yucatán en el contexto novohispano y luego independiente fue considerada la raíz determinante de estas disyuntivas yucatecas en la república mexicana por un número crecido de investigaciones. Algunos estudios explicaron la dinámica sociopolítica peninsular, mostrando cómo las fracturas étnicas se cruzaron con intereses políticos y mercantiles encontrados sobre la distribución del poder político en la península y la conformación de nuevas territorialidades en el ámbito regional y nacional. Al caracterizar y explicar las supuestas tendencias independentistas, secesionistas o separatistas de las elites yucatecas frente a los gobiernos de la república mexicana, varios autores arrojaron luz sobre el accionar de individuos y grupos de políticos y de interés en la península, preguntándose por qué los proyectos separatistas de las elites yucatecas "se quedaron en el camino". ${ }^{9} \mathrm{La}$ investigación de Flores Escalante consigue dar un giro frente a los estudios que lo precedieron, invirtiendo la pregunta acerca de la conflictividad y excepcionalidad yucateca, y su díscolas tendencias "separatistas": ¿por qué, finalmente, no se independizó Yucatán de México durante la independencia y hasta la Guerra con Estados Unidos entre 1846-1848?

La respuesta estriba en el devenir y construcción de la soberanía tanto en el ámbito peninsular como en la nación mexicana, nos dice el autor, proceso

El estudio pionero de Cline, "The sugar episode in Yucatan", pp. 79-100.

Tal el caso de Campos, Que los yucatecos todos proclamen su independencia, p. 19. Los estudios de esta propia autora también se enmarcaron en estas preocupaciones. La fragmentación del poder, y las imbricaciones y tensiones en el gobierno local —ayuntamientos y gobierno estatal - son discutidas en las investigaciones de Marco Bellingeri, Arturo Güémez Pineda, Othón Baños Ramírez, Terry Rugeley, Melchor Campos García, Laura Machuca y Karen Kaplan, entre otros. 
que estudia y examina con detenimiento a lo largo de cuatro capítulos y cuatro originales anexos documentales: "Los primeros planteamientos de la soberanía y el Pacto, 1821-1825"; "El Centralismo yucateco y la Nación mexicana, 1929-1932”, “El Estado excepcional o Nación Independiente, 1839-1843”, y finalmente "Reincorporación o anexión: la muerte de la nación yucateca, 1943-1848".

El estudio cuenta con el soporte de un exhaustivo corpus de información de primera mano reunida en archivos de México, Yucatán, Campeche y Estados Unidos, que recupera sesiones capitulares y legislativas, debates secretos, dictámenes y proclamas originales casi desconocidos o citados en estudios previos sólo a partir de referencias secundarias o transcripciones en la prensa. De forma sintética y contundente, esta obra confirma la importancia que tiene la investigación histórica bien orientada para recuperar fuentes documentales originales que permiten reconstruir y explicar el pasado. ${ }^{10} \mathrm{Si}$ bien se echa en falta mayor discusión del autor con la amplia y diversa historiografía anglosajona sobre el tema, el trabajo se recuesta en la historiografía que debate los legados del liberalismo gaditano en el liberalismo y republicanismo mexicano. Al lado, se nutre de las ricas investigaciones de las últimas décadas sobre la primera república federal y la época del centralismo en México.

Los cinco capítulos consiguen explicar el dificultoso proceso de integración de la península yucateca a la república mexicana, a través de su análisis de los cambios en la concepción y ejercicio de la soberanía, y mediante una trama de acontecimientos detallada, que arroja luz sobre hechos, personajes y acciones de los pueblos de la península yucateca. Brindan información y argumentos para la comprensión de la dinámica política e institucional yucateca en los tres niveles del gobierno (municipal, estatal y nacional). Al lado, dan atención detenida al juego de intereses, poderes y proyectos fraguados en el puerto de Campeche y los pueblos liderados por la ciudad de Mérida, sumando nueva información y análisis al proceso de formación de instituciones de gobierno representativo en el ámbito local y provincial (la península de Yucatán) durante el proceso de construcción del estado-nación en México. Cabe destacar, por último, que el conjunto de capítulos no sólo logra historizar la soberanía, sino además desmenuzar la construcción conceptual y política de la supuesta "excepcionalidad" yucateca a lo largo de la primera mitad del siglo XIX, desde las luchas por el libre comercio a las desventuras diplomáticas durante la Guerra del 47 con Estados Unidos.

Justo Flores Escalante consigue demostrar que hubo muchos más elementos de conexión e integración entre la península yucateca y el resto de México que los reconocidos por buena parte de la historiografía y cronistas de época: "en realidad, la historiografía ha magnificado el problema del separatismo

10 El libro es resultado de una investigación de tesis doctoral en el Centro de Estudios Históricos de El Colegio de México, dirigida por la doctora Josefina Zoraida Vázquez. 
yucateco y ha ignorado que probablemente hubo más lazos de unión entre Yucatán y México de lo que se ha supuesto", p. 273. Su estudio demuestra que el problema histórico del llamado "secesionismo" o "separatismo" yucateco de las primeras décadas de México independiente, legitimado por la investigación histórica regional, descansaba en la construcción de la idea de excepcionalidad de la península en el septentrión. Ésta se convirtió en un concepto esencial a la identidad regional yucateca desde el siglo xIX, un mito identitario que los historiadores contribuyeron después a reforzar. Su libro interroga exitosamente la cuestión de la excepcionalidad, rompiendo así con algunos supuestos de la historiografía regional, o al menos, poniéndolos en cuestión seria y rigurosamente. En ello reside una de sus principales aportaciones: su intento de deconstrucción documentada de la idea de excepcionalidad, y su análisis histórico, que cuestiona con nuevas preguntas a la historiografía y estudios yucatecos precedentes.

Al igual que las otras nuevas naciones emergentes de las guerras de emancipación en Hispanoamérica, la cohesión de la república mexicana nacida en 1824 fue frágil. Durante casi media centuria estuvo acosada por discordias políticas, la debilidad de sus gobiernos, la fragmentación a manos de los poderes regionales, y las tendencias centrífugas que explotaban por su territorio, así como por las reclamaciones e intereses extranjeros. Soberanía y excepcionalidad, la integración de Yucatán al Estado mexicano, 1821-1848, ilustra parte de esas discordias y también de las convergencias, encuentros y conciliaciones que dieron cimiento a la república, por lo que resulta de interés para los estudiosos de la formación de la república mexicana. Brinda elementos para repensar los procesos de desintegración de México de los pueblos que conformaron las repúblicas centroamericanas, y para revisar los avatares de la integración de Chiapas a la nación mexicana. Asimismo, su lectura, muy recomendable para cursos de historia latinoamericana, puede aportar al análisis comparativo de la conformación de repúblicas federales en Hispanoamérica independiente, incluso como contrapunto contrastante de otras discordias casi tan pronunciadas como las yucatecas: las pugnas confederalistas en los Andes, y los conflictos y armonías a ambas márgenes del Río de La Plata, entre 1810 y 1850 .

\section{Bibliografía}

Campos García, Melchor, Que los yucatecos todos proclamen su independencia, Mérida, Ediciones de la Universidad Autónoma de Yucatán, 2002.

Cline, Howard F., "The sugar episode in Yucatan, 1825-1850", Inter-American Economic Affairs, I, 1948, pp. 79-100.

De Landa, Diego, Relación de las cosas de Yucatán, c.1566. 
Gilbert Joseph, Rediscovering the Past at Mexico's Periphery: Essays on the History of Modern Yucatan, Alabama, The Alabama University Press, 1986.

González Navarro, Moisés, Raza y Tierra. La guerra de castas y el henequén, México, El Colegio de México, 1970.

López de Cogolludo, Diego, Historia de Yucatán, 1688.

Palacios, Guillermo, "Los bostonians, Yucatán y los primeros rumbos de la arqueología americanista estadounidense, 1875-1894”, Historia Mexicana, vol. 62, núm. 1, 2012, pp. 105-193.

Stephens, John Lloyd, Viaje a Yucatán, 1841-1842, México, Museo Nacional de Arqueología, Historia y Etnografía, 1937, 2 v.

"Yucatán en el tiempo", <https://es.wikipedia.org/wiki/Yucat\%C3\%A1n_en_el_ tiempo>, [consultado el 2 de julio de 2018]. 